Archived version from NCDOCKS Institutional Repository http://libres.uncg.edu/ir/asu/

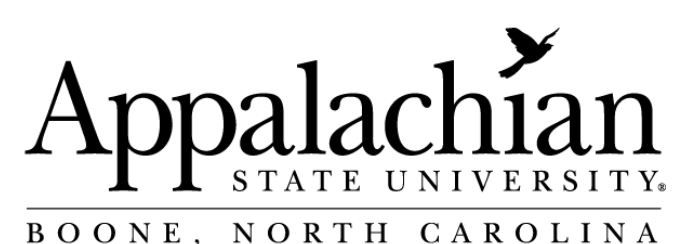

B O O N E, N O R T H C A R O L I N A

\title{
New Evidence On The Effect Of Belief Heterogeneity On Stock Returns
}

\author{
By: Jeffrey Hobbs, Hei Wai Lee, and Vivek Singh
}

\begin{abstract}
We develop a new measure to examine the effect of the heterogeneity of beliefs among investors on stock returns. Our initial results do not support the information asymmetry hypothesis or the sidelined investor hypothesis (and thus are consistent with the unbiased prices hypothesis). However, since the first two hypotheses make opposite predictions regarding stock returns, they may both have merit but offset one another. Further analysis suggests that this is indeed the case. Overall, our results support both the information asymmetry and sidelined investor hypotheses and thus occupy middle ground in the debate on the effect of disagreement on stock returns.
\end{abstract}

Hobbs, J., Lee, H.W. \& Singh, V. Rev Quant Finan Acc (2017) 48: 289. https://doi.org/10.1007/s11156-016-0551-7.

Publisher version of record available at: https://link.springer.com/article/10.1007/s11156-016-0551-7 


\section{New Evidence On The Effect Of Belief Heterogeneity On Stock Returns}

By: Jeffrey Hobbs, Hei Wai Lee, and Vivek Singh

\section{Abstract}

We develop a new measure to examine the effect of the heterogeneity of beliefs among investors on stock returns. Our initial results do not support the information asymmetry hypothesis or the sidelined investor hypothesis (and thus are consistent with the unbiased prices hypothesis). However, since the first two hypotheses make opposite predictions regarding stock returns, they may both have merit but offset one another. Further analysis suggests that this is indeed the case. Overall, our results support both the information asymmetry and sidelined investor hypotheses and thus occupy middle ground in the debate on the effect of disagreement on stock returns.

\section{Keywords}

Institutional investors, Divergence of opinion, Sidelined investors, Shorting constraints, Information asymmetry, Unbiased prices

\section{Introduction}

Beginning with Blackwell and Dubins (1962) and Aumann (1976) economists have focused on circumstances that make disagreement difficult in a rational setting. Aumann (1976) shows if agents share a common prior and have common knowledge of each other's posterior beliefs, they cannot agree to disagree. More recent work, however, shows that disagreement can arise even when agents have common priors and observe the same time series of public information. Acemoglu et al. (2006) argue, there are many empirical scenarios where permanent disagreement arises. In fact Acemoglu et al. (2006) demonstrate that agreement may be impossible, despite the fact that all agents update their beliefs as Bayesians.

Several empirical papers in finance have studied the effect of disagreement among investors on asset prices. There are three primary hypotheses associated with this stream of research. The first, to which we refer hereafter as the "information asymmetry hypothesis," posits that high levels of investor disagreement regarding a stock imply a high level of information asymmetry. 
This in turn suggests an initial discounting of a stock's price, i.e., low initial returns, followed by high subsequent returns to compensate for its high level of risk (see Williams 1977; Varian 1985; Merton 1987; Kraus and Smith 1989; Wang 1993; Harris and Raviv 1993; He and Wang 1995; Naik 1997).

The second hypothesis, which was originally developed by Miller (1977), posits that high levels of disagreement lead to "optimistic prices" when there exist restrictions against short-selling..$^{1}$ Because only the pessimistic investors are restricted from participating in the market for that stock, the stock's price will therefore reflect the opinion of the more optimistic investors.

We designate this the "sidelined investor hypothesis.” Morris (1996), Chen et al. (2002), and Viswanathan (2002) offer alternative explanations for optimistic investors' participation in stock markets. Naturally, the greater the level of shorting constraints or the greater the level of disagreement, the more upwardly biased the price and hence the initial return will be. When this overvaluation reverses, we will observe negative abnormal returns for the stock. Thus, the first two hypotheses come to opposite conclusions; the first suggests low initial and high subsequent returns, while the second suggests high initial and low subsequent returns.

It is quite plausible that the aforementioned competing hypotheses may be at play simultaneously in the market, neutralizing the effect of each other or through another mechanism that results in unbiased prices. In fact, there is a third hypothesis, which has not received as much attention in the empirical asset pricing literature, which leads to similar conclusions albeit employing different arguments. This hypothesis is attributed to Diamond and Verrecchia (1987) and Hong and Stein (2003). The central prediction of their models is that prices remain unbiased despite the presence of disagreement among investors. Consequently, future abnormal returns will, on average, be close to zero. These models rely on the existence of influential rational agents. While Diamond and Verrecchia (1987) require a perfectly rational market maker with unlimited computational abilities and access to all public information, Hong and Stein (2003) depend on the presence of perfectly rational arbitrageurs to eliminate any mispricing. We refer to this hypothesis hereafter as the "unbiased prices hypothesis."

Unfortunately, disagreement among investors is not directly observable. Therefore, researchers have used various proxies to investigate the influence of heterogeneous beliefs on asset prices and future returns and not surprisingly have arrived at conflicting conclusions. Diether et al. (2002) use dispersion in analysts' earnings forecasts as a proxy and find that the dispersion of opinion relates negatively to future returns. Park (2005) extends this work by testing whether the aggregate stock market becomes overpriced when differences in expectations are high. Park (2005) find that the dispersion in expectations among market analysts has predictive power for future stock returns: higher dispersion predicts lower stock returns. Cheng and Huang (2015) find similar results for Taiwan stock markets for 1990 to 2008. Yu (2011) finds that the ex post market return is negatively related to the bottom-up disagreement amongst analysts. Liu and Seasholes (2011) examine dual-listed shares in China and Hong Kong and show that when there is a short-sale ban in China, the prices of Chinese stocks are 1.8 times higher compared to those in Hong Kong. Similarly Chen et al. (2002) find compelling support for the Miller hypothesis in several markets in which there are binding short-sale constraints. However, Boehme et al. (2009) and Avramov et al. (2009) find evidence to the contrary. Goetzmann and Massa (2005) examine 
trading data from investor accounts to construct their measure of disagreement and find that disagreement relates positively to contemporaneous returns and negatively to future returns. Their findings also suggest that over-optimism, and not additional risk factors, is the dominant force driving returns. Hu et al. (2007) also find that disagreement among buy-side managers precedes low returns, especially for stocks that have constraints on short-selling. In summary, these studies employing different measures of investor disagreement find evidence corroborating Miller's (1977) sidelined investor hypothesis.

Doukas et al. (2006) use a measure free of the confounding effects of analysts' forecasts and find that future stock returns are positively associated with divergence of opinion, which is consistent with the information asymmetry hypothesis. The information asymmetry hypothesis is also supported by Garfinkel and Sokobin (2006), who find that the divergence of opinion, as measured by unexpected trading volume, is positively related to post-earnings announcement drift in stock returns. The authors thus conclude that divergence of opinion constitutes a priced risk factor. Similarly, Cragg and Malkiel (1982) report a positive relation between dispersion in analysts' forecasts and future returns for a sample of firms between 1961 and 1969. However, the studies that use analysts' forecasts to proxy disagreement suffer from another problem.

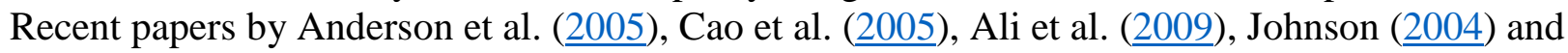
Qu et al. (2004) contend that the relationship between analysts' forecast dispersion and future returns can be explained by factors other than divergence in opinion and optimistic valuation. In summary, the various measures of the heterogeneity of beliefs lead to conflicting results depending on the measure employed. Hence, the collective weight of the empirical evidence has to date left the issue unresolved.

This paper proposes a new measure of disagreement to examine the implications of divergence of opinion on asset prices. Our new measure captures the level of disagreement in a stock in a quarter as the absolute value of the difference between the number of institutional investors buying and the number of institutional investors selling, scaled by the total number of institutional investors trading the stock. If disagreement is high then we expect the number of institutional investors buying and selling the stocks to be almost equal. Thus, low values of this measure ("institutional ratio") imply a high level of disagreement among institutional investors. In a recent article, Garfinkel (2009) also proposes a new proxy constructed from proprietary data to capture difference of opinion among investors. We not only provide a new measure that uses publicly available information, but also apply it to the much larger database and obtain new results for the impact of heterogeneous beliefs on asset prices.

There are at least two advantages of our measure over the proxies being used to capture disagreement among investors or divergence of opinion in the literature. First, since our measure focuses on the actual buying and selling behavior of institutions, we capture disagreement in a natural and explicit way. Unlike the different ways in which investors interpret a firm's earnings forecasts, or instances of abnormal trading that may be due to reasons other than difference of opinion, the basic divergence with respect to buying and selling a stock in a particular time period is an obvious and unambiguous sign of disagreement. Second, to improve the power of the empirical tests, it may be more appropriate to use measures that have been shown in the literature to meaningfully influence asset prices, such as institutional trading (see Gompers and 
Metrick 2001; Nofsinger and Sias 1999; Yan and Zhang 2009). Our measure has this advantage as well.

Our paper contains several unique findings. First, the level of agreement for different stocks varies widely within the buy-side of the market. Additionally, there are several factors that are associated with the level of disagreement. A high level of disagreement is associated with stocks with high (relative) abnormal turnover, market capitalization, institutional trading and ownership, as well as stocks with low sales growth, price volatility, book-to-market ratios, and, interestingly, a low dispersion of analysts' earnings forecasts and greater analyst coverage.

Our main findings are as follows. Within the sample of high-disagreement stocks, there is a positive and significant average contemporaneous quarterly abnormal return, which is predicted by the sidelined investor hypothesis. However, this is followed by another positive average abnormal return in the subsequent month; thus, we fail to detect the reversal predicted by the sidelined investor hypothesis. Additionally, the positive abnormal return contemporaneous to the quarter of disagreement is not significantly higher for high-disagreement stocks than it is for low-disagreement stocks, signifying a further lack of evidence for the sidelined investor hypothesis. Thus, our first set of results appears inconsistent with the information asymmetry and sidelined investor hypotheses.

Although it initially appears that our results give qualified support to the unbiased prices hypothesis of Diamond and Verrecchia (1987) and Hong and Stein (2003), further analysis is required. Because the information asymmetry and sidelined investor hypotheses make opposite predictions for stock returns, it is possible that both have merit and that the two opposing forces are simply canceling one another out. This seems especially plausible for stocks that exhibit a high degree of both shorting constraints and information asymmetry, which is often the case, i.e., the intersection of these two groups is likely to be a high percentage of their union. For example, small stocks that suffer a great degree of information asymmetry are also subject to a high level of shorting constraints. In order to test these two competing hypotheses against the unbiased prices hypothesis, we conduct three additional rounds of analysis. First, we sort the subsample of high-disagreement stocks by each of the three proxies for information asymmetry: firm size, book-to-market ratio and the dispersion of analysts' earnings forecasts, respectively, and compare the contemporaneous and subsequent returns to each subsample based on the level of information asymmetry. Second, we perform a similar comparison on the basis of short-selling constraints, alternately using institutional holdings and idiosyncratic volatility as proxies. Third, we conduct double-sorts based on both firm size and shorting constraints to further examine the interplay among the three hypotheses as well as their individual importance. While the one-way sorting indicates some support for the information asymmetry hypothesis and no support for the sidelined investor hypothesis, the two-way sorting procedure offers considerable evidence of both. Thus it appears that to an extent the two hypotheses are supported by the data but tend to cancel one another out for many of the stocks in our sample, therefore initially giving the third hypothesis (unbiased prices) the appearance of empirical support. 
We use the stock-holdings data of institutional investors to construct our sample of stocks about which investors hold divergent opinions. A 1978 amendment to the Securities and Exchange Act of 1934 requires all institutions managing more than $\$ 100$ million of securities to report their holdings to the SEC. The holdings are reported on form 13-F on a quarterly basis for all exchange-traded or NASDAQ-quoted equity securities within 45 days of the end of each quarter. These institutions are required to report any equity position greater than either 10,000 shares or $\$ 200,000$ in market value. These requirements set out the conditions for mandatory reporting of holdings. However, some institutions voluntarily report their holdings of all stocks. Interestingly, the dataset also includes hedge funds as long as they meet the requirements listed above. We use Thomson Financial 13-F data to obtain the quarterly stock holdings of all institutions between the fourth quarter of 1980 and the second quarter of 2010.

We extract stock returns data from the Center for Research in Security Prices (CRSP, hereafter) monthly files. We exclude ADRs (American Depositary Receipts), SBIs (Shares of Beneficial Interest), Units (Depository Units, Units of Beneficial Interest, Units of Limited Partnership Interest, Depository Receipts, etc.), REITs (Real Estate Investment Trusts), and closed-end funds from our sample. Thus our final sample consists of common stocks within the intersection of the CRSP monthly files and institutional investors' holdings databases from the fourth quarter of 1980 to the second quarter of 2010, i.e. 122 quarters. Our analysis is based on 564,214 stockquarters for which we have information on all relevant variables. Thus in an average quarter we have 4625 stocks that were traded by institutions.

\subsection{Measure of disagreement}

We base our measure of the level of disagreement among investors on institutional investors' holdings data. Our measure focuses on the disagreement in trading among institutional investors for a stock in a quarter. To proxy for the degree of disagreement among institutional investors, we construct the following metric:

$$
\mathrm{I}(\mathrm{i}, \mathrm{t})=|N B(i, t)-N S(i, t)| N B(i, t)+N S(i, t)
$$

We designate this the institutional ratio. Here, $N B(i, t)$ is the number of institutional investors who buy stock i in quarter $t . N S(i, t)$ is the number of institutional investors who sell stock i in quarter $t$. Therefore the numerator in the institutional ratio, $\mathrm{I}(\mathrm{i}, \mathrm{t})$, reflects the absolute value of excess of buyers over sellers of stock $\mathrm{i}$ in quarter $\mathrm{t} . \stackrel{2}{ }$ The denominator is simply the total number of institutional investors who traded stock i in quarter t. Since it takes at least two investors to disagree, we compute this measure for only those stock-quarters that had two or more institutional traders. If all institutional investors end up buying or selling stock i in quarter $t$, then $\mathrm{I}(\mathrm{i}, \mathrm{t})$ would equal 1 , which is indicative of a high degree of agreement with respect to the stock's prospects. On the other hand, if there is an equal number of buyers and sellers for stock i in quarter $t$, then I $(\mathrm{i}, \mathrm{t})$ would be 0 . It is reasonable to assume that this signifies a high level of 
disagreement among institutional investors. Therefore I(i,t) may range from 0 to 1 and lower values of I(i,t) are consistent with a greater degree of disagreement.

Since institutional investors do not buy or sell a stock due to informational reasons only, we employ several adjustments to ensure that our measure of disagreement, $I(i, t)$, is not contaminated by other motives for institutional trading. The adjustments control for possible impacts on the institutional ratio that could be due to the return on the existing holding of stock $i$ and the net flow of funds to the institutional investor during the current quarter, $t$. In the first step we use the following formula, which is inspired by Barber et al. (2005), and Griffin et al. (2011), to determine whether for each stock i in quarter $\mathrm{t}$ an institutional investor $\mathrm{K}$ is a buyer (Inst $(\mathrm{i}, \mathrm{t})$ is positive) or a seller (Inst $(\mathrm{i}, \mathrm{t})$ is negative).

$\operatorname{Inst}(i, t)=S_{i, t} P_{i, t}-S_{i, t-1} P_{i, t-1}\left(1+r_{i}\right) S_{i, t-1} P_{i, t-1}-\sum_{i=m i=1} S_{i, t} P_{i, t}-\sum_{i=m i=1} S_{i, t} P_{i, t-1}(1+r i) \sum_{i=m i=1} S_{i, t-}$ ${ }_{1} P i, t-1$

In this expression, $\mathrm{S}_{\mathrm{i}, \mathrm{t}}$ and $\mathrm{S}_{\mathrm{i}, \mathrm{t}-1}$ represent the number of shares held by a particular institutional investor $K$ in stock $i$ at the end of quarter $t$ and $t-1$, respectively. $P_{i, t}$ and $P_{i, t-1}$ are the share price of stock $i$ at the end of quarter $t$ and $t-1$, respectively. The return for stock $i$ in the current quarter $t$ is captured by $r_{i}$. Therefore, the first term in Eq. (2) computes the net buying or selling of stock $i$ in quarter $t$ by institutional investor $\mathrm{K}$ as a fraction of its initial holding of the stock, adjusted for the return on stock $\mathrm{i}$ in the current quarter. The second term computes the net buying or selling by the same institutional investor $\mathrm{K}$ across all $\mathrm{m}$ stocks traded in quarter $\mathrm{t}$. If institutional investor $\mathrm{K}$ faces an inflow (outflow) of funds in quarter $t$, we expect the second term to be positive (negative). Therefore Inst $(i, t)$ measures the level of buying or selling of stock $i$ in quarter $t$ that is over and above the net inflow or outflow of funds to institutional investor $\mathrm{K}$, adjusted for stock return. In addition, we adjust the shareholdings and prices for stock-splits and stock dividends in our computation. It is worth noting that we concentrate on whether an institution is a net buyer or seller of a stock rather than the number or dollar amount of shares traded by the institutional investor. We believe that for the purposes of capturing disagreement among institutional investors, whether an institution buys or sells a stock is more important than the dollar amount or the number of shares it trades. $\frac{3}{-}$

We denote $B^{K}(i, t)$ and $S^{K}(i, t)$ as the respective count for institutional buyers and sellers of stock $i$ in quarter $t$, and assign a value of 1 to $B^{K}(i, t)$ and 0 to $S^{K}(i, t)$ if the value of $\operatorname{Inst}(i, t)$ in Eq. (2) is positive. Similarly we assign a value of 1 to $S^{\mathrm{K}}(\mathrm{i}, \mathrm{t})$ and 0 to $B^{\mathrm{K}}(\mathrm{i}, \mathrm{t})$ if the value of Inst $(\mathrm{i}, \mathrm{t})$ is negative. We compute this measure for each stock $i$ traded by each institution in quarter $t$. Therefore, $N B(i, t)$ and $N S(i, t)$ in Eq. (1) are computed as follows:

$N B(i, t)=\sum K=1 K=N B K(i, t)$

(3)

and

$N S(i, t)=\sum K=1 K=N S_{K}(i, t)$

(4) 
where $\mathrm{N}$ denotes the total number of institutions trading stock $\mathrm{i}$ in quarter $\mathrm{t}$.

Furthermore, we use the following filters to ensure that our results based on the institutional ratio, I(i,t) in Eq. (1), are unaffected by issues other than the difference in opinion arising out of information. As a new stock comes to the market via an IPO in a quarter, most institutions will be net buyers and hence I(i,t) will be inflated. To alleviate this problem, we compute I(i,t) for only those stocks that existed in the previous quarter, $\mathrm{t}-1$. Similarly, I(i,t) will be deflated for those quarters when stocks go out of existence due to merger, acquisition, delisting, etc. To correct for this potential bias, we exclude the quarter when a stock exited the sample from the computation of I(i,t).

Similar to IPOs, seasoned equity offerings may also affect the institutional ratio. As a proxy for seasoned equity offerings, we assume that if the number of shares outstanding (adjusted for stock-splits, stock dividends, etc.) for a stock has increased by more than $25 \%$ from the previous quarter, then the stock has had a potential seasoned equity offering in the current quarter. ${ }^{4}$ We remove such stock-quarters from our final sample.

Since the performance of many institutions is benchmarked against stock market indexes, part of the institutional trading in stocks may be explained by indexing. To eliminate the effect of indexing on our results, we remove all stock-quarters that were affected by additions and deletions to the S\&P 500 during the sample period. In order to do this, we downloaded a file from Professor Jeffrey Wurgler's website, which contains all additions and deletions to the S\&P 500 index. This file contains the company identifier, addition or deletion flag, announcement date and effective date for addition to (or deletion from) the index, among other variables. If the level of trading in a stock is related to its addition to (or deletion from) the S\&P 500, we expect most of it to occur around the quarter of addition to (or deletion from) the index. We determine the quarter and year of addition or deletion for all stocks in this sample using the effective date and then merge it with our sample of stocks. We exclude from our final sample all stock-quarters in which additions or deletions occurred.

\subsection{Methodology}

Following the institutional investor literature, we adopt the methodology of Wermers (1999) to gauge the degree of disagreement on stock prices. In the spirit of Fama and MacBeth (1973), we examine quarterly cross-sectional contemporaneous abnormal returns and the subsequent months' average abnormal returns of the stocks for which investors hold different opinions. One may reason that much of the reversal following the quarter of disagreement (denoted Qtr 0) will occur immediately afterwards. We capture this reversal by reporting the monthly abnormal returns for each of the 3 months (denoted $M+1, M+2$, and $M+3$ ) in the subsequent quarter (denoted Qtr 1). We expect the reversal to be the greatest in the first month, i.e., $M+1$.

If the "information asymmetry hypothesis' describes the effect of disagreement on stock prices, then we expect stocks with a higher (lower) degree of disagreement in the current quarter to have not only lower (higher) abnormal returns contemporaneously, but also higher (lower) abnormal returns in the subsequent quarter. By contrast, the "sidelined investor hypothesis" predicts that stocks with a higher (lower) degree of disagreement in the current quarter will have not only 
higher (lower) abnormal returns contemporaneously, but also lower (higher) abnormal returns in the subsequent quarter. Last, the "unbiased prices hypothesis" postulates that disagreement has no impact on stock prices. Hence, we do not expect any relationship between abnormal returns in the contemporaneous quarter and subsequent abnormal returns conditioned on the difference of opinion. Any abnormal returns observed merely represent the incorporation of new information into prices via the trading of institutional investors.

In order to compute quarterly abnormal returns, we first compute monthly abnormal returns using the Fama-French (1993) model augmented with the momentum factor introduced by Carhart (1997). We download the factors from Kenneth French's website. To compute the abnormal return of each stock i, we regress the stock's monthly excess return on the three factors of Fama and French (1993) and the momentum factor in Carhart (1997) as follows: $r_{i, t}-r_{f, t}=\alpha_{i}+\beta_{i}\left(r_{m, t}-r_{f, t}\right)+\gamma_{i}\left(s m b_{t}\right)+\delta_{i}\left(h m l_{t}\right)+\omega_{i}$ $\left(m_{\mathrm{t}}\right)+\varepsilon_{\mathrm{i}, \mathrm{t}}$. In particular, $r_{i, t}-r_{\mathrm{f}, \mathrm{t}}$ is the excess return of stock i over the 1-month T-bill yield, which proxies for the risk-free rate in month $t$; the first factor, $r_{m, t}-r_{f, t}$, denotes the excess return of the valueweighted return on all NYSE, AMEX and NASDAQ stocks over the 1-month T-bill yield in month $t$; the second factor, $\mathrm{smb}_{\mathrm{t}}$, is the difference between the respective returns of small and large capitalization stocks in month $\mathrm{t}$; the third factor, $\mathrm{hml}_{\mathrm{t}}$, is the difference between the respective returns of high and low book-to-market stocks in month $\mathrm{t}$; and the fourth factor, $\operatorname{mom}_{\mathrm{t}}$, is the difference between the respective returns of stocks with high and low recent returns in month $t$. The asset-pricing factor models state that $\alpha_{i}=0$, and $\varepsilon_{i, t}$ is orthogonal to information known in month $t-1$. T The abnormal return for stock $i$ in month $\mathrm{t}$ is given by this formula:

$A R i, t=r i, t-r f, t-\beta \wedge_{i}(r m, t-r f, t)-\gamma \wedge i(s m b t)-\delta \wedge_{i}(h m l t)-\omega^{\wedge} \wedge_{i}(m o m t)=\alpha^{\wedge}{ }_{i}+\varepsilon^{\wedge} \wedge_{i, t .}$

To compute the abnormal return in a quarter, we compound the 3 monthly abnormal returns for stock $\mathrm{i}$ for that quarter.

\subsection{Descriptive statistics}

Although not tabulated here, we find that the time-series mean (median) of the quarterly crosssectional average of the institutional ratio is $0.244(0.217)$, ranging from a high of 0.923 to a low of 0.140 . When we sort the sample into three groups based on market capitalization every quarter, we observe an inverse relationship between the institutional ratio and firm size, averaging 0.331 for the smallest stocks and decreasing monotonically to 0.159 for the largest stocks. This is consistent with the idea that investors have a greater divergence of opinion for larger stocks. Similarly, when we sort the stocks based on institutional holdings, we observe that the mean institutional ratio is 0.190 for the group of stocks with the highest level of institutional holdings and 0.308 for those with the lowest level of institutional holdings. This implies that investors have a higher divergence of opinion for stocks with low shorting constraints, to the extent that institutional holdings proxy for shorting constraints.

Table 1 offers a comparison between stocks about which there is a high level of disagreement and those that experience a low level of disagreement. The variables selected for each stock are its return volatility over the previous 12 months, the dispersion of analysts' earnings forecasts, abnormal trading volume over the previous four quarters, market capitalization, price-to-earnings ratio, book-to-market ratio, the number of institutional trades, the percentage of shares outstanding that is held by institutions, the 
number of analysts covering the stock, past returns, and growth in sales over the past year. We provide further details regarding the computation of these variables in Table 1 . Figures in boldface signify a difference between high- and low-disagreement stocks that is statistically significant at the $1 \%$ level.

Table 1

Stock characteristics and the degree of disagreement

\section{Stock variable}

Volatility

Dispersion

Stock turnover

Size

$\mathrm{P} /$ E ratio

Book-to market ratio

Number of Institutional trades

Institutional holdings

Analyst coverage

Past returns

Sales growth
Disagreement among institutions

High disagreement Low disagreement

$12.410 * * * \quad 15.420 * * *$

$0.083^{* * *}$

0.016

12.562**

$36.109 * * *$

0.716***

92.495***

42.000***

8.846***

$0.082 * * *$

$1.772 * * *$
$0.430 * * *$

$-0.013$

$10.818 * * *$

$37.529 * * *$

1.052***

26.778***

$21.027 * * *$

$3.648 * * *$

$0.072 * * *$

$2.622 * * *$

This table shows variable means for high and low levels of disagreement between institutional investors. The degree of disagreement among institutional investors is captured by the "institutional ratio", which is computed for each stock in each quarter traded by institutions as detailed in the text. Volatility is the standard deviation of a stock's past 12 months of monthly returns. Dispersion is the standard deviation of analysts' earnings forecasts scaled by the closing stock price on the trading day preceding the forecast date. The standard deviation of the forecasts is based on the IBES Summary Historical files. Stock turnover is the mean excess turnover of a stock computed from the past 4 quarters of exchange-adjusted quarterly turnover. Size is the natural logarithm of market capitalization, which is the market price multiplied by shares outstanding extracted from the CRSP monthly files. To compute P/E ratio, price is taken at the end of the month from the CRSP files and earnings is extracted from the annual COMPUSTAT files (data item \#233). We use the most recent earnings if the firm's fiscal year is within 90 days of the current month-otherwise we use the prior year's earnings and end-of fiscal year price per share. Book-to-Market ratio is the ratio of book value of equity to market value of equity. Book Value is taken from the COMPUSTAT annual files and market value is market price multiplied by shares outstanding extracted from the CRSP monthly files. Institutional holding is the fraction of equity held by institutional investors in a particular quarter. Analyst coverage is the number of valid estimates used to compute the mean earnings forecast and is extracted from the IBES Historical Summary files. Past return is the preceding 6 months' abnormal returns based on the Carhart 4-factor model. We compound monthly abnormal returns to compute the 6 month return. Sales growth is the average sales growth of the firms in the analyst portfolios. To compute sales growth, we divide the current fiscal year's sales with the previous fiscal year's sales. Sales are 
extracted from the COMPUSTAT annual files (data item \#12). Similar to the P/E ratio, we use the most current sales growth if the firm's financial year ends within 90 days of the current month; otherwise we use the prior year's sales growth. We compute the cross-sectional mean of each variable for each group of stocks in each quarter and then take the time-series average for the entire time-period. $* * *, * *$, and * signify statistical significance at the 1,5 and $10 \%$ level respectively. The variables whose difference in means between high and low disagreement are statistically different have values listed in bold

Our results show that among institutions, disagreement is concentrated in stocks with relatively low sales growth, price volatility, and book-to-market ratios, as well as stocks with high market capitalization, analyst coverage, institutional holdings, and trading. Interestingly, stocks with a lower dispersion of analysts' earnings forecasts and high abnormal turnover tend to experience a higher degree of disagreement among institutions. It is noteworthy that prior studies have used dispersion in analysts' earnings forecasts and abnormal turnover as proxies of disagreement among investors. Thus our measure captures a new dimension of disagreement.

\section{Results}

\subsection{Initial results}

Table $\underline{2}$ presents a time-series of the cross-sectional average of quarterly and monthly abnormal stock return statistics, sorted by the level of disagreement, for the stocks traded by institutions. "Qtr 0 " refers to the quarter in which the disagreement occurred (this number is computed on a quarterly basis because our agreement/disagreement observations are quarterly), while "Qtr 1" refers to the abnormal returns of the following quarter. " $M+1$ ", “ $M+2$ " and " $M+3$ " refer to the abnormal returns of the 3 months in Qtr 1, respectively. - When institutions disagree most about a stock (see the "HD" tercile), the contemporaneous quarterly abnormal return $(0.48 \%)$ is positive and significant, the following month's return $(0.29 \%)$ is significantly positive, and the returns in the next 2 months are again positive, though statistically insignificant. The difference in the contemporaneous quarter abnormal returns between stocks in the high (HD) and low (LD) disagreement terciles is insignificant as well. Thus these initial results presented in Panel A are consistent with neither the "information asymmetry hypothesis" nor the "sidelined investor hypothesis". Further, we conduct a robustness check by sorting our sample into quintiles instead of terciles. As reported in Panel B of Table $\underline{2}$, the results are similar to those reported in Panel A as highlighted in the above discussion. Since we perform double-sorting of the sample in subsequent analysis, we adopt tercile grouping to ensure larger sample sizes in order to enhance the power of the tests.

Table 2

Stock returns when institutions disagree

$$
\text { Institutional ratio } Q \operatorname{Qtr} 0 \quad \text { Qtr } 1 \quad M+1 \quad M+2 \quad M+3
$$

Panel A: Degree of disagreement amongst institutions and stock returns

High disagreement (HD)

$$
\begin{array}{llllll}
0.042 & 0.480 & 0.324 & 0.286 & 0.035 & 0.071
\end{array}
$$




\begin{tabular}{|c|c|c|c|c|c|c|}
\hline & Institutional ratio & Qtr 0 & Qtr 1 & $\mathbf{M}+\mathbf{1}$ & $\mathbf{M}+2$ & $\mathbf{M}+3$ \\
\hline & 0.176 & 0.229 & 0.417 & 0.361 & 0.022 & 0.018 \\
\hline Medium disagreement (MD & & & & & & \\
\hline & $(<0.000)$ & $(0.326)$ & $(0.089)$ & $(0.003)$ & $(0.824)$ & $(0.856)$ \\
\hline & 0.506 & 0.427 & 0.600 & 0.986 & 0.016 & -0.227 \\
\hline Low disagreement (LD) & $(<0.000)$ & $(0.352)$ & $(0.172)$ & $(<0.000)$ & $(0.928)$ & $(0.216)$ \\
\hline & -0.464 & 0.053 & -0.276 & -0.700 & 0.0188 & 0.299 \\
\hline
\end{tabular}

HD-LD

$$
(<0.000) \quad(0.915)(0.574)(0.007) \quad(0.929)(0.152)
$$

Panel B: Degree of disagreement amongst institutions and stock returns

High disagreement (HD)

$$
\begin{array}{llllll}
0.019 & 0.487 & 0.365 & 0.411 & -0.002 & 0.038
\end{array}
$$

$\begin{array}{llllll}(<0.000) & (0.044) & (0.181) & (0.001) & (0.982) & (0.747) \\ 0.086 & 0.427 & 0.234 & 0.131 & 0.046 & 0.096\end{array}$

MD4
$(<0.000)$
(0.034) (0.215) (0.191) (0.611) (0.279)
0.174
$\begin{array}{lllll}0.225 & 0.520 & 0.406 & 0.051 & 0.007\end{array}$

MD3

$\begin{array}{llllll}(<0.000) & (0.330) & (0.056) & (0.001) & (0.610) & (0.944) \\ 0.290 & 0.009 & 0.457 & 0.663 & 0.023 & -0.128\end{array}$

MD2

Low disagreement (LD)

$\begin{array}{llllll}(<0.000) & (0.981) & (0.160) & (0.000) & (0.876) & (0.361) \\ 0.642 & 0.729 & 0.629 & 1.160 & 0.003 & -0.274\end{array}$

$(<0.000) \quad(0.169)(0.216)(<0.000)(0.987)(0.202)$

HD-LD

$-0.623$

$-0.242-0.264-0.705-0.0060 .313$

$(<0.000)$

(0.676) (0.645) (0.022) (0.980) (0.202)

This table compares the contemporaneous and future returns of stocks conditioned on the degree of disagreement among institutional investors. The degree of disagreement among institutional investors is captured by institutional ratio which is computed for each stock in each quarter traded by institutions as detailed in the text. Qtr 0 refers to the quarter in which the agreement/disagreement occurred, while $\mathrm{M}+1, \mathrm{M}+2$ and $\mathrm{M}+3$ refer to the abnormal returns of the subsequent 3 months. We compute the cross-sectional mean of the abnormal returns for each group of stocks in each quarter and then take the time-series average for the entire time period. All abnormal returns are based on the Carhart 4-factor model. To compute the monthly abnormal returns of the stocks, we regress excess stock returns on the excess market, size, bookto-market, and momentum factors. We download excess market return, size, book-to-market, and momentum factors from Kenneth French's website. The abnormal return (in \%) in each month is the sum of the monthly residual and intercept from our regressions. $P$ values based on two-tailed $t$ tests are shown in parentheses 


\subsection{Disagreement, firm size, and stock returns}

In our further examination of the information asymmetry hypothesis, we sort stocks that are subject to a high level of disagreement into terciles based on firm size. Firm size has been suggested as a proxy for information asymmetry (Frankel and Li (2004), and Wermers (1999) among others), wherein part of the extra risk associated with smaller firms is said to derive from a lack of publicly available information. Firm size is measured by the natural logarithm of market capitalization, computed as the share price at the start of the quarter multiplied by the number of shares outstanding extracted from the CRSP monthly files. Panel A of Table $\underline{3}$ displays the cross-sectional average of quarterly and monthly abnormal returns for the size-based terciles.

Table 3

Disagreement, firm size, and stock returns

$$
\begin{array}{lllll}
\text { Qtr 0 } & \text { Qtr 1 } & \text { M + 1 } & \text { M + 2 } & \text { M + 3 }
\end{array}
$$

Panel A: Abnormal return when institutions disagree sorted on firm size

$\begin{array}{llllll} & -2.222 & 0.769 & 1.750 & -.0 .14 & -0.207 \\ \text { S1 (smallest firms) } & (<0.001) & (0.163) & (<0.001) & (0.945) & (0.328) \\ \text { S2 (middle) } & 1.618 & 0.157 & -0.095 & 0.007 & 0.253 \\ & & & & & \\ & (<0.001) & (0.469) & (0.373) & (0.948) & (0.030) \\ & 2.043 & 0.045 & -0.221 & 0.111 & 0.166\end{array}$

S3 (largest firms)

$\begin{array}{lllll}(<0.001) & (0.811) & (0.06) & (0.299) & (0.143) \\ -4.267 & 0.724 & 1.396 & -0.126 & -0.373\end{array}$

S1-S3

$$
\begin{array}{lllll}
(<0.001) & (0.105) & (<0.001) & (0.592) & (0.119)
\end{array}
$$

Panel B: Abnormal return when institutions disagree sorted on book to market ratio

BM1 (low book-to market firms)

$$
\begin{array}{lllll}
4.366 & -0.084 & -0.085 & -.0 .015 & -0.044
\end{array}
$$

BM2 (mid book-to market firms)

$\begin{array}{lllll}(<0.001) & (0.780) & (0.569) & (0.903) & (0.766) \\ 0.899 & 0.478 & 0.139 & 0.132 & 0.263\end{array}$

BM3 (high book-to market firms)

$\begin{array}{lllll}(<0.001) & (0.017) & (0.139) & (0.178) & (0.017) \\ -3.528 & 1.037 & 0.680 & 0.272 & 0.232\end{array}$

$\begin{array}{lllll}(<0.001) & (0.005) & (0.000) & (0.065) & (0.080) \\ 7.894 & -1.121 & -0.765 & -0.287 & -0.276 \\ & & & & \\ (<0.001) & (0.018) & (0.001) & (0.139) & (0.165)\end{array}$

Panel C: Abnormal return when institutions disagree sorted on analysts' earnings forecasts dispersion 


\begin{tabular}{|c|c|c|c|c|c|}
\hline & Qtr 0 & Qtr 1 & $\mathbf{M}+\mathbf{1}$ & $\mathbf{M}+2$ & $\mathbf{M}+3$ \\
\hline \multirow{3}{*}{ DISP1 (low dispersion firms) } & 3.897 & 1.346 & 0.195 & 0.381 & 0.781 \\
\hline & $(<0.001)$ & $(<0.001)$ & $(0.179)$ & $(0.005)$ & $(<0.001)$ \\
\hline & 0.907 & 0.039 & -0.107 & 0.033 & 0.152 \\
\hline \multirow{2}{*}{ DISP2 (mid dispersion firms) } & $(<0.001)$ & $(0.850)$ & $(0.303)$ & $(0.762)$ & $(0.172)$ \\
\hline & -2.978 & -0.885 & -0.243 & -0.196 & -0.406 \\
\hline \multirow[t]{2}{*}{ DISP3 (high dispersion firms) } & $(<0.001)$ & $(0.005)$ & $(0.117)$ & $(0.222)$ & $(0.000)$ \\
\hline & 6.875 & 2.231 & 0.438 & 0.576 & 1.319 \\
\hline DISP1-DISP3 & $(<0.001)$ & $(<0.001)$ & $(0.038)$ & $(0.006)$ & $(<0.001)$ \\
\hline
\end{tabular}

This table examines the abnormal returns, within different classes of firm size, for the case when investors are in disagreement. Firm size in Panel A is proxied by natural logarithm of market capitalization computed as the share price at the start of the quarter multiplied by the shares outstanding, extracted from the CRSP monthly files. In Panel B, Book-to-Market ratio is the ratio of book value of equity to market value of equity at the start of the quarter. Book Value is taken from the COMPUSTAT files and market value is market price multiplied by shares outstanding extracted from the CRSP monthly files. In Panel C, Dispersion is the standard deviation of analysts' earnings forecasts scaled by the closing stock price on the trading day preceding the forecast date. The standard deviation of the forecasts is based on the IBES Summary Historical files. We examine the abnormal returns for the group of stocks with the highest level of disagreement amongst institutional investors sorted by firm size/book-market ratio/dispersion in analyst forecast. To identify the groups of stocks with the highest level of disagreement, stocks are sorted in three groups each quarter on the basis of institutional ratio as detailed in the text. The stocks with the lowest value of institutional ratio are categorized as the stocks with the highest level of disagreement among institutional investors. We compute the cross-sectional mean of abnormal returns for each group of stocks in each quarter and then take the time-series average for the entire time period. All abnormal returns are based on the Carhart 4-factor model. Qtr 0 is the quarter in which disagreement occurs. Returns are the cumulative abnormal returns for the 3 months of the contemporaneous quarter 0 and the abnormal returns for the first 3 months afterward: M1, M2, and M3. To compute the monthly abnormal return of the stocks, excess stock returns are regressed on the excess market, size, book-to-market, and momentum factors. We download excess market return, size, book-to-market, and momentum factors from Kenneth French's website. The abnormal return (in \%) in each month is the sum of the monthly residual and intercept from our regressions. $P$ values based on two-tailed $t$ tests are shown in parentheses

Each group in a typical quarter has about 515 stocks. The smallest firms have negative average abnormal returns $(-2.22 \%)$ during the quarter of disagreement. This is consistent with the information asymmetry hypothesis, which posits that such firms are initially discounted most, in response to their greater level of riskiness. 
However, this risk-discounting argument also predicts higher returns in subsequent periods as compensation for higher risk. We do, in fact, witness this reversal in the subsequent month. The reversal following disagreement is striking; the first month's abnormal return $(1.75 \%)$ mirrors roughly $80 \%$ of the initial decline and is significant at the $0.1 \%$ level. Moreover, the difference between the abnormal returns to the smallest and largest firm size terciles is also significantly negative in the contemporaneous quarter and positive in the following month. In addition, the reversal over the full quarter following disagreement can be considered marginally significant within the context of a one-way (predictive or "directional”) test. We interpret the findings reported in Table $\underline{3}$ as being supportive of the information asymmetry hypothesis.

To check for the robustness of these results, we also examine the book-to-market ratio as a proxy for asymmetric information in Panel B. We sort the sample into terciles by the book-to-market ratio calculated at the beginning of each quarter. We find that in the quarter of disagreement our high book-to-market or "distressed" firms (tercile BM3) have an average abnormal return of $-3.53 \%$ and a partial but highly significant reversal of $+1.04 \%$ in the following quarter, which is again compatible with the information asymmetry hypothesis. In contrast, we find a significantly positive average abnormal return of $4.37 \%$ in the quarter of disagreement for the low book-to-market or "growth" firms tercile (BM1), and an insignificant negative abnormal returns in the following period. However, this seems to be largely a result of a high degree of intersection between our low book-to-market ratio tercile of firms and our large-size tercile; low book-to-market ratio firms make up roughly half (48.9\%) of the large-firms tercile. Thus we conclude that, for the most part, the evidence is consistent with the information asymmetry hypothesis that investors react to the information risk associated with the quality of distressed firms with negative returns in the contemporaneous quarter followed by a partial reversal in the following quarter.

Given the extensive intersection of the book-to-market ratio sample and the firm size sample, the results of the book-to-market proxy may be confounded with those of the firm size proxy. As a further robustness check on the supportive evidence for the information asymmetry hypothesis, we use the dispersion in analysts' earnings forecasts as an alternate proxy for asymmetric information in Panel $\mathrm{C}$ of Table $\underline{3}$. We sort our sample stocks into terciles by the dispersion in analysts' forecasts, which is computed as the standard deviation of analysts' earnings forecasts scaled by the closing stock price on the trading day preceding the forecast date. We find a significant average abnormal return of $-2.98 \%$ in the quarter of disagreement for high information asymmetry firms that are included in the highest dispersion tercile, but a highly significant continuation of $+0.89 \%$ in the next quarter. In addition, we find a significantly positive average abnormal return of $3.90 \%$ in the quarter of disagreement for low information asymmetry firms, i.e., the lowest dispersion tercile. Thus current quarter abnormal returns are consistent with the information asymmetry hypothesis, though we do not observe any reversal in subsequent quarters. Overall we can we still conclude that, for the most part, the evidence is consistent with the information asymmetry hypothesis, which predicts that stocks with a high degree of information asymmetry will experience negative abnormal returns in the quarter of disagreement and a partial reversal in the following quarter. 


\subsection{Disagreement, short-sales constraints and stock returns}

In our further examination of the role of the sidelined investors hypothesis in explaining the effect of investor disagreement on asset prices, we first determine the presence of sidelined investors by examining changes in the level of short interest. If sidelined investors exist then we would expect short-sales constraints to influence stock returns. We postulate that a high volatility in the level of short interest implies that the sidelined investor hypothesis has a limited role in explaining stock returns. However, persistence in the level of short interest (i.e. a lack of volatility) might signify the presence of sidelined investors. We download the monthly short interest data for the period of 1974 to 2010 from the COMPUSTAT supplemental files. We divide the month-end aggregate short interest by the number of shares outstanding to compute the monthly short interest ratio for each stock for which there is data in COMPUSTAT. We make appropriate adjustments for share splits, stock dividends, etc. We estimate an AR (1) model by regressing the current period's short interest ratio on the previous period's short interest ratio. A lack of persistence in the short-interest ratio would imply the coefficient in the AR (1) model to be no different from zero. Instead, we find the coefficient to be a highly significant 0.878; thus the level of short interest is quite stable. This result indicates that sidelined investors are present and may potentially influence share prices.

In order to examine the sidelined investor hypothesis more closely, we sort our stocks into terciles by institutional ownership and report in Table $\underline{4}$ the abnormal returns surrounding the quarter of disagreement. Institutional ownership is inversely related to constraints on short-selling (Boehmer and Kelley (2009), and Zhao et al. (2006)), so a low level of institutional ownership is expected to at first yield "optimistic prices," according to Miller (1977), followed by negative abnormal returns. This should be especially true in the case of a high level of disagreement, both according to Miller (1977) and the empirical findings of Boehmer et al. (2006). Instead, we find that the contemporaneous abnormal returns in our low-ownership, high-shorting-constraints tercile $(\mathrm{H} 1)$ are lower than those in our highownership, low-constraints tercile (H3) for cases of disagreement among institutions.

Table 4

Disagreement, short-sales constraints, and stock returns

$$
\begin{array}{lllll}
\text { Qtr } 0 & \text { Qtr } 1 & \text { M + 1 } & \text { M + } 2 & \text { M + 3 }
\end{array}
$$

Panel A: Abnormal return when institutions disagree sorted on short-sales constraints (IH based)

H1 (highest constraints)

$$
0.004 \quad 0.549 \quad 0.984 \quad-0.093 \quad-0.216
$$

$\begin{array}{llllll} & (0.992) & (0.272) & (0.000) & (0.620) & (0.287) \\ \text { H2 (medium constraints) } & 0.334 & 0.250 & 0.334 & 0.109 & 0.142 \\ & (0113) & (0.245) & (0.745) & (0.276) & (0.167) \\ \text { H3 (lowest constraints) } & 1.159 & 0.171 & -0.161 & 0.090 & 0.286\end{array}$




\begin{tabular}{lllllll} 
& & Qtr 0 & Qtr 1 & \multicolumn{1}{c}{$\mathbf{M}+\mathbf{1}$} & $\mathbf{M}+2$ & $\mathbf{M}+3$ \\
& $(0.000)$ & $(0.399)$ & $(0.202)$ & $(0.453)$ & $(0.021)$ \\
H1-H3 & -1.155 & 0.378 & 1.145 & -0.184 & -0.503 \\
& $(0.020)$ & $(0.482)$ & $(<0.001)$ & $(0.408)$ & $(0.034)$
\end{tabular}

Panel B: Abnormal return when institutions disagree sorted on short-sales constraints (IVOL based)

IVOL 1 (highest constraints)

$\begin{array}{lllll}0.270 & -0.084 & 0.622 & -0.180 & -0.384\end{array}$

$\begin{array}{lllll}(0.633) & (0.870) & (0.012) & (0.339) & (0.064)\end{array}$

$\begin{array}{lllll}0.756 & 0.570 & 0.164 & 0.188 & 0.213\end{array}$

IVOL 2 (medium constraints)

$\begin{array}{lllll}(0.001) & (0.007) & (0.130) & (0.188) & (0.213) \\ 0.418 & 0.485 & 0.069 & 0.097 & 0.385\end{array}$

IVOL3 (lowest constraints)

IVOL1-IVOL3

$\begin{array}{lllll}(0.070) & (0.011) & (0.514) & (0.361) & (<0.001) \\ -0.150 & -0.570 & 0.553 & -0.277 & -0.769\end{array}$
(0.807)
(0.299)
(0.041)
$(0.200) \quad(0.000)$

This table examines the abnormal returns, within different classes of short-sales constraints, for the cases when investors are in disagreement. In Panel A, short-sales constraints in each stock are proxied by the aggregate level of holding by all institutional investors for a particular quarter as reported in the Thomson 13-F files. In Panel B, short-sales constraints in each stock are proxied by idiosyncratic volatility calculated using Fama-Fench 3 factor as detailed in the text. We examine the abnormal returns for the group of stocks with the highest level of disagreement among institutional investors sorted by short-sales constraints. To identify the group of stocks with the highest level of disagreement, stocks are sorted in three groups each quarter on the basis of institutional ratio as detailed in the text. The stocks with the lowest value of institutional ratio are categorized as the stocks with the highest level of disagreement among institutional investors. We compute the cross-sectional mean of abnormal returns for each group of stocks in each quarter and then take the time-series average for the entire time period. All abnormal returns are based on the Carhart 4-factor model. Qtr 0 is the quarter in which disagreement occurs. Returns are the cumulative abnormal returns for the 3 months of the contemporaneous quarter 0 and the abnormal returns for the first 3 months afterward: M1, M2, and M3. To compute the monthly abnormal return of the stocks, excess stock returns are regressed on the excess market, size, book-to-market, and momentum factors. We download excess market return, size, book-tomarket, and momentum factors from Kenneth French's website. The abnormal return (in \%) in each month is the sum of the monthly residual and intercept from our regressions. $P$ values based on two-tailed $t$ tests are shown in parentheses

Furthermore, abnormal returns in both the subsequent month and subsequent quarter are opposite to what is predicted by the sidelined investor hypothesis, both in absolute terms and relative to the abnormal returns of those firms that are the least constrained. 
In order to check the robustness of these results, we use idiosyncratic volatility as an alternate proxy for short-sales constraints, consistent with prior literature, in Panel B. To compute idiosyncratic volatility (IVOL) during month $t$, we regress the daily excess return of each stock I on the contemporaneous daily Fama and French (1993) factors as follows:

$\mathrm{ri}, \mathrm{d}-\mathrm{rf}, \mathrm{d}=\alpha \mathrm{i}+\beta \mathrm{i}(\mathrm{rm}, \mathrm{d}-\mathrm{rf}, \mathrm{d})+\gamma_{\mathrm{i}}(\mathrm{smbd})+\delta_{\mathrm{i}}(\mathrm{hmld})+\varepsilon \mathrm{i}, \mathrm{d}$,

where $r_{i, d}-r_{f, d}$ is the daily excess return of stock i over the 1-month T-bill yield on day $d ; r_{m, d}-r_{f, d}$, denotes the daily excess return of the value-weighted return on all NYSE, AMEX and NASDAQ stocks over the 1-month T-bill yield on day $\mathrm{d}$; $\mathrm{smb}_{\mathrm{d}}$, is the difference between the respective returns of small and large capitalization stocks on day $\mathrm{d}$; and $\mathrm{hml}_{\mathrm{d}}$, is the difference between the respective returns of high and low book-to-market stocks on day $\mathrm{d}$.

The monthly idiosyncratic volatility of stock $i$ in month $t$ is defined as the standard deviation of the residuals from this regression multiplied by the square root of the number of trading days in the month:

IVOLi,t $=\operatorname{var}\left(e_{i, d}\right)---\_---\sqrt{ } \times D_{t}-\sqrt{ }$,

In the equation above, $D_{t}$ is the number of trading days for stock $i$ in month $t$. The results reported in Panel $B$ of Table 4 , which are based on sorting the sample into terciles on idiosyncratic volatility, are similar to those in Panel A. Thus, we find no evidence in Table $\underline{4}$ to support the sidelined investor hypothesis that shorting constraints cause "optimistic prices" and a subsequent correction.

\subsection{Separating the effect of information asymmetry from that of shorting constraints}

Throughout this paper, we use institutional ownership as the primary proxy for short-selling constraint and firm size for information asymmetry. However, there could be some interaction between these variables-for example, institutional ownership increases with firm size, suggesting that the most constrained firms, which have the lowest institutional ownership, also tend to have the highest degree of information asymmetry, i.e., the smallest capitalization. Such interaction imposes a challenge to judge the merits of the "information asymmetry hypothesis" and the "sidelined investor hypothesis" with respect to one another. Additionally, because these two hypotheses yield opposite empirical predictions on the influence of disagreement on asset prices, it is also difficult to judge how they compare to that of the "unbiased prices hypothesis".

Thus far, the initial results based on our full sample appear to lend support to the unbiased prices hypothesis. However, when we sort the full sample by firm size and by institutional ownership, respectively, we find support for the information asymmetry hypothesis and no support for the sidelined investor hypothesis. Hence, it is important to note that our initial results do not unambiguously support the unbiased prices hypothesis of Diamond and Verrecchia (1987) and Hong and Stein (2003). It could be the case that both the sidelined investor and information asymmetry hypotheses have merit but their opposite effects on stock returns cancel out one another in the initial results, thus giving the misleading appearance of evidence in favor of the unbiased prices hypothesis. In the following sections, we perform more direct tests that intend to disentangle the sidelined investor hypothesis from the information asymmetry hypothesis. Our further analysis may also offer conclusive findings regarding the validity of the unbiased prices hypothesis in explaining the impact of disagreement on asset prices. 
We begin by further examining the abnormal returns reported in Tables $\underline{3}$ and $\underline{4}$ through the prism of an independent sort. - First, we group our high-disagreement sample into terciles based on institutional ownership, and then separately into terciles based on market capitalization. This independent sort results in nine (three-by-three) groups of sample stock-quarters. We then report in Table $\underline{5}$ the abnormal returns of the four groups covering the bottom ("S1") and top ("S3") size terciles interacting with the bottom ("H1") and top ("H3") institutional ownership terciles.

Table 5

Disagreement, short-sales constraints, firm size and stock returns

$$
\begin{aligned}
& \text { Panel A (most constrained; H1) Panel B (least constrained; H3) }
\end{aligned}
$$

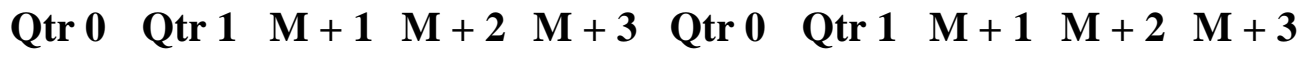

Abnormal return when institutions disagree sorted on short-sales constraints

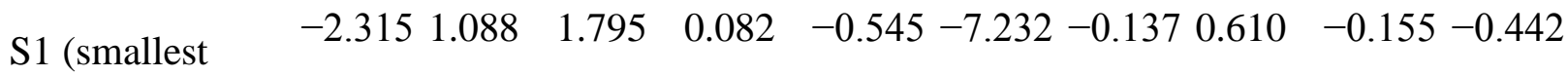

$$
\begin{aligned}
& \text { firms) } \\
& \text { S3 (largest } \\
& \text { (0.000) (0.150) (0.000) (0.771) (0.060) (0.000) (0.823) (0.077) (0.616) (0.145) } \\
& \text { firms) }
\end{aligned}
$$

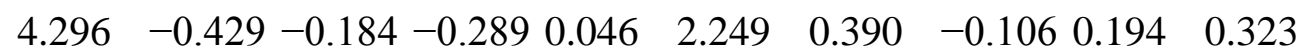

$$
\begin{aligned}
& \text { (0.000) (0.125) (0.239) (0.079) (0.775) (0.000) (0.060) (0.390) (0.065) (0.007) }
\end{aligned}
$$

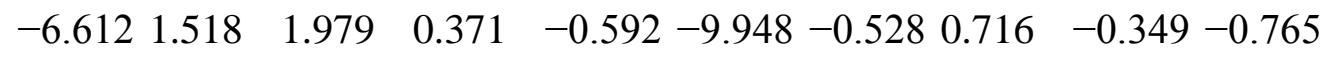

$$
\begin{aligned}
& \text { (0.000) (0.059) (0.000) (0.255) (0.074) (0.000) (0.415) (0.050) (0.285) (0.019) }
\end{aligned}
$$

Abnormal return when institutions disagree sorted on firm size

$$
\begin{aligned}
& \text { H1 (most } \quad-2.315 \quad 1.088 \quad 1.795 \quad 0.082 \quad-0.545 \quad 4.296 \quad-0.429-0.184-0.2890 .046 \\
& \text { constrained) } \\
& \text { (0.000) (0.150) (0.000) (0.771) (0.060) (0.0.125) (0.239) (0.079) (0.775) } \\
& \text { H3 (least }
\end{aligned}
$$

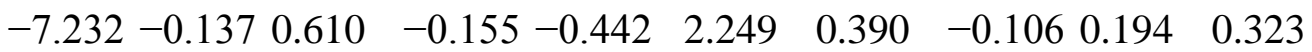

$$
\begin{aligned}
& \text { constrained) } \\
& \text { (0.000) (0.823) (0.077) (0.616) (0.145) (0.000) (0.060) (0.390) (0.065) (0.07) }
\end{aligned}
$$

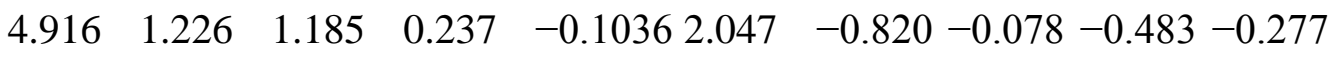

$$
\begin{aligned}
& \text { (0.000) (0.208) (0.024) (0.571) (0.00171) (0.018) (0.013) (0.013) }
\end{aligned}
$$

This table examines the abnormal returns when investors are in disagreement sorted independently by short-sales constraints and by firm size. Firm size is proxied by natural logarithm of market capitalization computed as the share price at the start of the quarter multiplied by the shares outstanding, extracted from the CRSP monthly files. Short-sales constraints in each stock are proxied by the aggregate level of holding by all institutional investors for a particular quarter as reported in the Thomson 13-F files. We examine the abnormal returns for the group of stocks with the highest level of disagreement among institutional investors sorted by short-sales constraints and firm size independently. To identify 
the group of stocks with the highest level of disagreement, stocks are sorted in three groups each quarter on the basis of institutional ratio as detailed in the text. The stocks with the lowest value of institutional ratio are categorized as the stocks with the highest level of disagreement among institutional investors. We compute the cross-sectional mean of abnormal returns for each group of stocks in each quarter and then take the time-series average for the entire time period. All abnormal returns are based on the Carhart 4-factor model. Qtr 0 is the quarter in which disagreement occurs. Returns are cumulative abnormal returns for the 3 months of the contemporaneous quarter 0 and abnormal returns for the first 3 months afterward: M1, M2, and M3. In order to compute the monthly abnormal return of the stocks, excess stock returns are regressed on the excess market, size, book-to-market, and momentum factors. We download excess market return, size, book-to-market, and momentum factors from Kenneth French's website. The abnormal return (in \%) in each month is the sum of the monthly residual and intercept from our regressions. $P$ values based on two-tailed $t$ tests are shown in parentheses

Panel B presents results for the subset of stocks that are the least shorting-constrained (highest level of institutional ownership, "H3”). Therefore, the abnormal returns of the smallest size tercile ("S1") are the most likely to be affected by the presence of asymmetric information. Hence, the "S1" section of Panel B represents a favorable scenario for testing the information asymmetry hypothesis, which predicts low abnormal returns in the contemporaneous quarter followed by high abnormal returns in subsequent months. We find a highly significant average abnormal return of $-7.23 \%$ in the quarter of disagreement and a relatively small (but marginally significant) reversal of $0.61 \%$ in the subsequent month. Moreover, the difference in the abnormal returns of $-9.95 \%$ between the smallest and largest firms in Panel B (the row titled “S1-S3") also supports the information asymmetry hypothesis, although the first month's reversal of $0.72 \%$ is again relatively small despite its statistical significance.

Panel D provides us with the results of a fairly direct test of the sidelined investor hypothesis, since the firms therein are large ("S3") and thus unlikely to have significant information asymmetry. As the sidelined investor hypothesis predicts, the most shorting-constrained firms ("H1”) experience initially high abnormal returns of $4.30 \%$ in the quarter of disagreement and then a reversal, which is though small and marginally significant only for a one-sided test, in the following quarter. However, the difference between the abnormal returns to the bottom and top institutional ownership terciles (shown in the row labeled "H1-H3”) constitutes further evidence in favor of the sidelined investor hypothesis. The most constrained firms display significantly higher contemporaneous-quarter and lower subsequent-quarter abnormal returns than the lessconstrained firms of the largest firms within the subsample. Thus, in each case where we use one subsample of companies that are less likely to be affected by one hypothesis in order to test the other hypothesis, we find supportive evidence for the hypothesis being examined.

Although Panels B and D of Table $\underline{5}$ provide results for the most direct tests of the information asymmetry and sidelined investor hypotheses, respectively, the results reported in Panels A and $\mathrm{C}$ provide further insight on the roles of these two hypotheses in explaining the effect of investor disagreement on stock returns. Panel A features highly shorting-constrained stocks ("H1"), i.e., those with the lowest level of institutional ownership. Similar to the results reported in Panel B, we find support for the information asymmetry hypothesis when we compare the abnormal returns for the top (“S3”) versus bottom (“S1”) size terciles. The abnormal returns that we 
observe both for firms with limited shorting constraints ("H3”) and for firms with a high level of shorting constraints ("H1") are consistent with the predictions of the information asymmetry hypothesis. This suggests that our results are robust to differences in shorting constraints. Additionally, the negative contemporaneous quarter's abnormal return for highly shortingconstrained stocks reported in Panel A is smaller in magnitude than that for less constrained stocks reported in Panel B. This suggests that the sidelined investor hypothesis partially offsets the information asymmetry hypothesis with regard to stock returns in cases of disagreement.

Panel C of Table $\underline{5}$ reports the abnormal returns for the tercile of firms experiencing the most information asymmetry ("S1"). When we examine the abnormal return differentials between the institutional ownership terciles (the row labeled "H1-H3”), we find higher, though negative, abnormal returns for the most shorting-constrained firms than for the least constrained firms. However, we find no evidence of a relative reversal in the following month or quarter. The positive abnormal return differential between the institutional ownership terciles reported in Panel C supports the sidelined investor hypothesis among firms with the most information asymmetry and suggests that our results are robust to differences in the degree of asymmetry. In addition, the negative abnormal returns to even the most shorting-constrained firms ("H1") in Panel C suggest that both hypotheses may be at work simultaneously within this subset of our sample and that the information asymmetry hypothesis at times dominates the sidelined investor hypothesis. This sheds new light on the results in Table $\underline{4}$, which initially did not appear to support the predictions of the sidelined investor hypothesis.

Overall, we interpret the results in Table $\underline{5}$ as supportive of both the information asymmetry and sidelined investor hypotheses. Further, we find evidence that the effects of the two forces are in some cases offsetting one another, which helps considerably to explain the results from our earlier tables. Thus, we conclude that the initial appearance of support for the unbiased prices hypothesis - and the appearance of a lack of support for either the information asymmetry or the sidelined investor hypothesis — is not sustained upon further investigation.

Though there is evidence that the information asymmetry hypothesis may have the upper hand in explaining the effect of investor disagreement on stock returns, both hypotheses do, in fact, appear to wield significant influence. Hence, care must be taken in disentangling their confounding effects.

\section{Conclusion}

In this study we create a new measure of disagreement based on institutional trades in order to examine how the divergence of opinion among investors affects stock returns. We use the imbalance of stock-level buying and selling as a percentage of institutional trading to measure agreement (low values imply greater disagreement). Three hypotheses regarding the effect of disagreement on stock returns currently exist: the sidelined investor hypothesis, which predicts high initial and low subsequent abnormal returns; the information asymmetry hypothesis, which predicts low initial and high subsequent abnormal returns; and the unbiased prices hypothesis, which predicts that abnormal returns concurrent with and subsequent to periods of investor disagreement will on average be insignificant. 
Our initial results, taken from the full sample, show little if any support for the information asymmetry hypothesis or the sidelined investor hypothesis. Thus at first blush the results appear consistent with the unbiased prices hypothesis. However, after sorting our sample by firm size, we find that for the smallest firms, disagreement among institutions does correspond to negative returns initially and an almost exact reversal in the following month as predicted by the information asymmetry hypothesis. When we sort our sample by institutional ownership as a proxy for shorting constraints and examine cases of disagreement, we find no evidence of positive initial returns followed by a reversal as predicted by the sidelined investor hypothesis. Additionally, when we employ alternative proxies for information asymmetry and shorting constraints, the results enumerated above remain largely unchanged.

Although these findings appear to reject the sidelined investor hypothesis and are supportive of the information asymmetry hypothesis, we cannot draw such a conclusion for two reasons. First, there can be interaction between the variables used to measure information asymmetry and shorting constraints. Second, the first two hypotheses make opposite predictions regarding the impact on stock returns of disagreement between investors. Thus it may be the case that both of the first two hypotheses are correct, but the opposing pressures on stock returns tend to offset one another, making the sidelined investor hypothesis appear not to be present when it may in fact be. Further analysis reveals that the companies that are likely to suffer from either-but not both-shorting constraints or information asymmetry do experience abnormal returns that are consistent with the predictions of the information asymmetry and sidelined investor hypotheses. We thus conclude that the weight of the evidence presented in this study supports these two hypotheses even though at first it appears otherwise.

\section{Footnotes}

1. 1.

Chen and Guo (2010) apply a version of Miller (1977) model in IPO settings to study many IPO related patterns.

2. 2 .

For the purposes of this paper, it is immaterial if the number of buyers is greater than the number of sellers or vice versa. This is because we are concerned about the difference in opinion among traders rather than their actual preferences with respect to buying or selling. In addition, the use of absolute values aids the analysis in the next section.

3. 3 .

We agree with the argument that stronger belief in a private signal will manifest itself in more buying or selling by an institution. Thus, the number of shares bought or sold may provide additional information. We believe our simpler measure performs as well and has the additional benefit that it helps us focus on the more fundamental issue of disagreement by removing the effect of greater dollar holdings by an institution. 
4. 4 .

We also used a more liberal $10 \%$ increase to proxy for seasoned equity offerings. This does not materially affect our results.

5. $\underline{5}$.

Additionally, we reproduced Tables $\underline{2}, \underline{3}, \underline{4}, \underline{5}$ and included the abnormal returns for months 4,5 , and 6 as well as months 1,2 , and 3 . The results remained unchanged. For the sake of brevity we do not report the results for months 4, 5 and 6 in this paper.

6. $\underline{6}$.

We also conducted various dependent sorts on firm size and institutional ownership. The results we obtained were very similar to those of the two independent sorts reported in Table $\underline{5}$.

\section{References}

1. Acemoglu D, Chernozhukov V, Muhamet $Y$ (2006) Learning and disagreement in an uncertain world. NBER working paper series, no. 12648

2. Ali A, Liu M, Xu D, Yao T (2009) Why does analysts' forecast dispersion predict stock returns? A corporate guidance perspective. Working paper SSRN

3. Anderson A, Ghysels E, Juergens J (2005) Do heterogeneous beliefs matter for asset pricing? Rev Financ Stud 18(3):875-924

4. Aumann R (1976) Agreeing to disagree. Ann Stat 4(6):1236-1239

5. Avramov D, Chordia T, Jostova G, Philipov A (2009) Dispersion in analysts' earnings forecasts and credit rating. J Financ Econ 91(1):83-101

6. Barber $B$, Odean $T$, Zhang $L$ (2005) Out of sight, out of mind: the effects of expenses on mutual fund flows. J Bus 78(6):2095-2119

7. Blackwell D, Dubins L (1962) Merging of opinions with increasing information. Ann Math Stat 33(7):882-886

8. Boehme R, Danielsen B, Kumar P, Sorescu S (2009) Idiosyncratic risk and the cross-section of stock returns: Merton (1987) meets Miller (1997). J Financ Mark 12(3):438-468

9. Boehmer E, Kelley E (2009) Institutional investors and the informational efficiency of prices. Rev Financ Stud 22(9):3563-3594

10. Boehmer R, Danielsen B, Sorescu S (2006) Short-sale constraints, dispersion of opinion and overvaluation. J Financ Quant Anal 41(2):455-487

11. Cao H, Wang T, Zhang H (2005) Model uncertainty, limited market participation and asset prices. Rev Financ Stud 18(4):1219-1251

12. Carhart M (1997) On persistence in mutual fund performance. J Finance 52(1):57-82

13. Chen H, Guo W (2010) Divergence of opinion and initial public offerings. Rev Quant Financ Account 34(1):59-79

14. Chen J, Hong H, Stein J (2002) Breadth of ownership and stock returns. J Financ Econ 66(23):171-205

15. Cheng $C$, Huang $Y$ (2015) Differences of opinion and price reversals: evidence from the Taiwan stock exchange. Rev Pac Basin Financ Mark 18(3):1500-1523 
16. Cragg J, Malkiel M (1982) Expectations and the Structure of Share Prices. University of Chicago Press, Chicago, IL

17. Diamond D, Verrecchia R (1987) Constraints on short-selling and asset price adjustment to private information. J Financ Econ 18(2):277-311

18. Diether K, Malloy C, Scherbina A (2002) Differences of opinion and the cross section of stock returns. J Finance 57(5):2113-2142

19. Doukas J, Kim C, Pantzalis C (2006) Divergence of opinion and equity returns. J Financ Quant Anal 41(3):573-606

20. Fama E, French K (1993) Common risk factors in the returns on stocks and bonds. J Financ Econ 33(1):3-56

21. Fama E, MacBeth J (1973) Risk, return, and equilibrium: empirical tests. J Polit Econ 81(3):607636

22. Frankel R, Li X (2004) Characteristics of a firm's information environment and the information asymmetry between insiders and outsiders. J Account Econ 37(2):229-259

23. Garfinkel J (2009) Measuring investors' opinion divergence. J Account Res 47(5):1317-1348

24. Garfinkel J, Sokobin J (2006) Volume, opinion divergence, and returns: a study of post-earnings announcement drift. J Account Res 44(1):85-112

25. Goetzmann W, Massa M (2005) Dispersion of opinion and stock returns. J Financ Mark 8(3):325350

26. Gompers P, Metrick A (2001) Institutional investors and equity prices. Q J Econ 116(1):229-259

27. Griffin J, Harris J, Shu T, Topaloglu S (2011) Who drove and burst the tech bubble? J Finance 66(4):1251-1290

28. Harris M, Raviv A (1993) Differences of opinion make a horse race. Rev Financ Stud 6(3):473-506

29. He H, Wang J (1995) Differential information and dynamic behavior of stock trading volume. Rev Financ Stud 8(4):919-972

30. Hong H, Stein J (2003) Differences of opinion, short-sales constraints, and market crashes. Rev Financ Stud 16(2):487-525

31. Hu G, Meng J, Potter M (2007) Opinion divergence among professional investment managers. J Bus Financ Account 35(5):679-703

32. Johnson T (2004) Forecast dispersion and the cross section of expected returns. J Finance 59(5):1957-1978

33. Kraus A, Smith M (1989) Market created risk. J Finance 44(3):557-569

34. Liu C, Seasholes M (2011) Dual-listed shares and trading. Working paper, Hong Kong University of Science and Technology

35. Merton R (1987) A simple model of capital market equilibrium with incomplete information. J Finance 42(3):483-510

36. Miller M (1977) Risk, uncertainty and divergence of opinion. J Finance 32(4):1151-1168

37. Morris S (1996) Speculative investor behavior and learning. Q J Econ 111(4):1111-1133

38. Naik N (1997) On aggregation of information in competitive markets: the dynamic case. J Econ Dyn Control 21(7):1199-1227

39. Nofsinger J, Sias R (1999) Herding and feedback trading by institutional and individual investors. J Finance 54(6):2263-2295

40. Park C (2005) Stock return predictability and the dispersion in earnings forecasts. J Bus 78(6):2351-2376

41. Qu S, Starks L, Yan H (2004) Risk, dispersion of analyst forecasts and stock returns. Working paper, SSRN

42. Varian H (1985) Divergence of opinion in complete markets: a note. J Finance 40(1):309-317 
43. Viswanathan S (2002) Strategic trading, heterogeneous beliefs/information, and short constraints. Working paper, Duke University

44. Wang J (1993) A model of intertemporal asset prices under asymmetric information. Rev Econ Stud 60(2):249-282

45. Wermers R (1999) Mutual fund trading and the impact on stock prices. J Finance 54(2):581-622

46. Williams J (1977) Capital asset prices with heterogeneous beliefs. J Financ Econ 5(2):219-239

47. Yan X, Zhang $Z$ (2009) Institutional investors and equity returns: are short-term institutions better informed? Rev Financ Stud 22(2):893-924

48. Yu J (2011) Disagreement and return predictability of stock portfolios. J Financ Econ 99(1):162183

49. Zhao H, Alexandridis G, Antoniou A (2006) Valuation effects of short sale constraints: the case of corporate takeovers. Euro Financ Manag 12(5):747-762 